The Journal of Rheumatology 2021;48:7

doi: $10.3899 /$ jrheum. 210093

First Release March 152021

\section{Dr. Naides replies}

\section{To the Editor:}

We thank Dr. Russell for raising the issue of reporting the false positivity rate of antinuclear antibody (ANA) indirect immunofluorescent assay (IFA) testing. ${ }^{1}$ It is difficult, however, for a laboratory to state a false positive rate, per se, as the determination of "falseness" is dependent on clinical evaluation that is typically not available to most laboratories. Further, any false positive rate determined by a translational study in a given laboratory will depend on the patient population served, the expertise of clinical evaluators ordering testing, and ordering patterns; it may also change with differences in patient populations and ordering practices. For example, an elderly population would be expected to generate more false positive ANAs. A rheumatology practice would be expected to be more selective in ordering ANAs and thereby generate fewer false positive results.

Dr. Russell accurately points out that results can be affected by altering testing method. ${ }^{1}$ As the correspondent has done, the intensity of the staining can be lessened by diluting conjugated secondary antibody. The intensity observed by the technician performing manual assessment can also be affected by microscope efficiency and individual observer visual light acuity and green light perception. Light perception efficiencies and thresholds can likewise be manipulated in automated platforms. As we noted in our study, ${ }^{2}$ fixation of HEp-2 cells tends to deplete SSA and tRNA synthetases, the autoantibody targets in Sjögren syndrome and inflammatory myositis/ pulmonary fibrosis, respectively. Hence, by purposely diluting conjugate, there is increased probability of missing certain autoantibodies during ANA IFA screening.
Rather than a laboratory modifying an assay to attempt to align laboratory results with a constantly changing patient population and practice, it would be best for the laboratory to strive toward standardization. Several manufacturers offer intensity standards based on the World Health Organization ANA standard serum pools. ${ }^{3}$ Standards for various patterns are also available from commercial sources. Finding and using a standard or set of standards within the laboratory would minimize interassay and interobserver variations, as well as promote interlaboratory concordance. Consistency in laboratory practice would allow clinicians to rely on results from the servicing laboratory and better compare those results from other laboratories where the patient has been tested during their diagnostic journey.

Stanley J. Naides (1) MD, FACP, FACR, Consultant SJN receives consultancy fees from AlphaSights, EUROIMMUN US, Guidepoint, Laboratory Corporation of America.

Address correspondence to Dr. S.J. Naides, 33072 Sunharbor, Dana Point, CA 92629, USA. Email: stanley.naides@gmail.com.

\section{REFERENCES}

1. Russell AS. The variability of antinuclear antibody testing. J Rheumatol 2021;48:1190.

2. Naides SJ, Genzen JR, Abel G, Bashleben C, Ansari MQ. Antinuclear antibodies testing method variability: a survey of participants in the College of American Pathologists' proficiency testing program. J Rheumatol 2020;47:1768-73.

3. Nakamura RM, Bylund DJ, Tan EM. Current status of available standards for quality improvement of assays for detection of autoantibodies to nuclear and intracellular antigens. J Clin Lab Anal 1994;8:360-8. 


\section{Correction}

COVID-19 in Children With Rheumatic Diseases in the Spanish National Cohort EPICO-AEP

Cristina Calvo, Clara Udaondo, and The Rheumatic Diseases EPICO-AEP Working Group

J Rheumatol 2021; doi: 10.3899/jrheum.201548

The following grant information should be included in the funding sources: This study has been funded by Project PI20/00095, from the Instituto de Salud Carlos III (Ministry of Economy, Industry and Competitiveness) and cofunded by the European Regional Development Fund.

doi: 10.3899/jrheum.201548.C1 